\title{
Medical Claim Cost Impact of Improved Diabetes Control for Medicare and Commercially Insured Patients with Type 2 Diabetes
}

\author{
Kathryn Fitch, RN, MEd; Bruce S. Pyenson, FSA, MAAA; and Kosuke Iwasaki, FIAJ, MAAA
}

\begin{abstract}
BACKGROUND: Diabetes prevalence is increasing in the United States, yet the control of critical clinical metrics (e.g., hemoglobin A1c [A1c], blood pressure, and lipids) remains suboptimal. Lower A1c levels have been shown to be associated with lower diabetes complication rates, and reduced medical costs have been reported in individuals with diabetes who have improved glycemic control. While many studies have quantified the impact of A1c control on medical claim costs, this article provides new information on the cost and event impact of better control for all 3 metrics for the commercial population and Medicare population separately.
\end{abstract}

OBJECTIVES: To (a) quantify current type 2 diabetes control rates for A1c, blood pressure, and lipids and (b) model the impact of scenarios for better control of these metrics on diabetes complication rates and complication costs in people with diabetes in commercially insured and Medicare populations.

METHODS: 858 adults with commercial $(n=392)$ or Medicare $(n=466)$ coverage and type 2 diabetes were identified from approximately 10,000 individuals in the National Health and Nutrition Examination Survey (NHANES; combined series 2005-2006 and 2007-2008). Based on each individual's risk factors, the United Kingdom Prospective Diabetes Study modeling tool was used to project rates of 7 diabetes complications under status quo A1C, blood pressure, and lipid levels and complication rates under better management. Three improved management scenarios were created to model the impact of better control in all commercially insured and Medicare individuals with type 2 diabetes who had A1c, blood pressure, or lipids not at goal and in a subset of individuals whose A1c levels were $\geq 7 \%$, with or without blood pressure or lipids not at goal. Thomson Reuters MarketScan Commercial Claims and Encounters Database (2006-2009) and Medicare $5 \%$ sample data (2006-2009), including the eligibility data for each, were used to develop both the average annual costs and per-patient-per-month (PPPM) costs, adjusted to 2012 dollars, in commercially insured and Medicare fee-for-service patients with diabetes and the cost of diabetesrelated complications to monetize the impact of reducing complications.

RESULTS: Analysis of NHANES data showed that type 2 diabetes prevalence is $6.1 \%$ in commercially insured individuals aged 20 to 64 years and $19.4 \%$ in Medicare beneficiaries aged 65 years and older. Of patients with type 2 diabetes, $47 \%$ of commercially insured patients and $38 \%$ of Medicare patients were found to have A1C $\geq 7 \%$. With improved control of A1c, blood pressure, and lipid levels that were not at goal, as modeled in 3 management scenarios, reductions in the probability of complications across all patients with diabetes ranged from $43 \%$ to $67 \%$ in the commercial population and $28 \%$ to $49 \%$ in the Medicare population. The cost savings effect from reduced complications across all patients with diabetes ranged from \$67 to \$105 PPPM in the commercial population and \$99 to \$158 in the Medicare population. The high end of this savings range yielded a reduction of about $10 \%$ in total costs when compared with an average of $\$ 1,090$ PPPM in commercially insured patients with diabetes and an average of $\$ 1,565$ PPPM in Medicare patients with diabetes derived from large claims databases, both in projected 2012 dollars.
CONCLUSION: Results of this analysis suggest that better control of A1c, blood pressure, and lipids is associated with savings opportunities in commercially insured and Medicare patients with type 2 diabetes. A focus on only patients with uncontrolled A1c offers a somewhat higher per-patient cost reduction than for all uncontrolled diabetes patients but greatly diminishes the number of targeted patients.

J Manag Care Pharm. 2013;19(8):609-20

Copyright $\odot 2013$, Academy of Managed Care Pharmacy. All rights reserved.

\section{What is already known about this subject}

- Diabetes control rates of critical clinical metrics, such as hemoglobin Alc ([Alc]; glycemic control), blood pressure (BP), and lipids, has improved in recent years but are still suboptimal, with 57\% control for Alc (Alc < 7\%), 45\% for BP (<130/80 mm Hg), and 47\% for low-density lipoprotein cholesterol (LDL-C $<100 \mathrm{mg}$ per dL).

- Improved control of Alc, BP, and lipids is associated with a lower rate of diabetes complications and lower medical costs.

- The United Kingdom Prospective Diabetes Study tools that quantify the probabilities of diabetes complications based on a patient's controllable and uncontrollable risk factors are well established and consider Alc, BP, and lipids.

\section{What this study adds}

- For people with diabetes, about $20 \%$ of the commercial or Medicare costs is due to diabetes complications. For scenarios of improved control over Alc, BP, and lipid levels, cost savings impact from reduced complications across all diabetes patients on a per-patient-per-month (PPPM) basis ranged from \$67 to \$105 in the commercial population and $\$ 99$ to $\$ 158$ in the Medicare population. The high end of this savings range yielded a reduction of about $10 \%$ in total costs relative to an average of $\$ 1,090$ PPPM in commercially insured patients with diabetes and an average of $\$ 1,565$ PPPM in Medicare patients with diabetes.

- For both the commercial and Medicare populations, the number of people with diabetes who have any of the 3 metrics uncontrolled was about twice the number who have Alc uncontrolled.

- The per-patient savings from better control is similar whether or not Alc is the metric that is uncontrolled. For the commercial population, the per-patient savings from better control for people with diabetes and uncontrolled Alc is $20 \%$ to $29 \%$ higher than if better control were applied to people with diabetes and any of the 3 metrics uncontrolled. For the Medicare population, the per-patient savings from better control was about $50 \%$ higher for patients with uncontrolled Alc compared with the patients with any of the 3 metrics uncontrolled. 
$\mathrm{T}$ he prevalence of diabetes is on the rise in the United States, with an increase in diagnosed diabetes from $6.5 \%$ in 1999 to $7.8 \%$ in $2006 .{ }^{1}$ Furthermore, the increase in prevalence is projected to continue; in fact, estimates suggest that diagnosed and undiagnosed diabetes will almost double between 2009 and 2034. ${ }^{2}$ Individuals with diabetes face an increased risk of microvascular and macrovascular disease (i.e., coronary artery disease, stroke, peripheral vascular disease, end-stage rental disease, and retinopathy), and the ageadjusted risk of death in individuals with diabetes is nearly twice that of those without diabetes. ${ }^{3}$

Although the control rate of critical clinical metrics, such as hemoglobin Alc (Alc; glycemic control), blood pressure (BP), and lipids, has improved in recent years, ${ }^{1}$ the management of diabetes is still suboptimal. A previous analysis of National Health and Nutrition Examination Survey (NHANES) data (combined series 2003-2004 and 2005-2006) shows that control rates remain low: $57 \%$ control for Alc (Alc < 7\%), 45\% for $\mathrm{BP}(\mathrm{BP}<130 / 80 \mathrm{~mm} \mathrm{Hg})$, and $47 \%$ for low-density lipoprotein cholesterol (LDL-C $<100$ milligrams per deciliter [mg/dL]). ${ }^{1}$ In addition, only $12.2 \%$ of individuals with diabetes in NHANES (2003-2006) were reported to have all 3 metrics simultaneously controlled. ${ }^{1}$

Landmark studies have reported that lower Alc levels are associated with lower rates of diabetes-related complications. ${ }^{4-6}$ However, studies do not uniformly report that lower Alc is better at all levels. The ACCORD trial ${ }^{7}$ identified higher mortality among patients with Alc $<6 \%$ compared with a control group with Alc of $7 \%-7.9 \%$.

The medical costs associated with type 2 diabetes are substantial, and the portion of the national health care expenditure attributed to its management is expected to increase from $10 \%$ in 2011 to $15 \%$ in $2031 .{ }^{8}$ Numerous diabetes management efforts invoke the urgency of controlling health care costs. Several medical cost impact studies have reported that medical costs are lower in individuals with diabetes who have improved glycemic control. ${ }^{8-14}$ Results of a retrospective analysis in 6,780 patients with diabetes who were members of a large U.S. health insurance plan showed that predicted total diabetes-related costs were $32 \%$ higher in patients with Alc levels $>7 \%$ than in those with Alc levels $\leq 7 \%$ ( $\$ 1,540$ vs. $\$ 1,171$, respectively; $P<0.001){ }^{9}$ A regression analysis used to estimate the correlation between glycemic control and medical costs in 3,017 patients with diabetes who were members of a large health maintenance organization (HMO) found that costs increased for every $1 \%$ increase above an Alc level of $7 \% .{ }^{10}$ In a study of 34,469 patients with type 2 diabetes identified from a large U.S. managed care organization, a 1-percentage point increase in Alc led to a $4.4 \%$ increase (on average) in diabetes-related medical costs, which corresponds to an annual cost increase of $\$ 250$ per person. ${ }^{11}$ A study investigating the benefit of intensive glycemic control, intensified hypertension control, and serum cholesterol reduction in a hypothetical cohort of newly diagnosed patients with type 2 diabetes reported incremental cost-effectiveness ratios of $\$ 41,384,-\$ 1,959$, and $\$ 51,889$, respectively, per quality-adjusted life-year. ${ }^{12}$ In a retrospective study of 2,394 patients with diabetes identified in a multispecialty group clinic, the adjusted rate of inpatient admissions (hospital or skilled nursing facility) over a 3-year period was 13 per 100 patients with good glycemic control (Alc < 8\%), 16 per 100 patients with fair glycemic control (Alc ranges 8\% to $10 \%$ ), and 31 per 100 patients with poor glycemic control (Alc $>10 \% ; P<0.05)$. The corresponding mean adjusted charges were about $\$ 970, \$ 1,380$, and $\$ 3,040$, respectively. ${ }^{13}$ Results of a retrospective cohort analysis in 9,887 patients with type 1 or type 2 diabetes who received care at a clinic affiliated with a managed care organization showed that the probability of a diabetes-related hospitalization was higher in patients with a mean Alc $\geq 10 \%$ than in those with a mean Alc $<7 \%$ (odds ratio $=2.14 ; 95 \%$ confidence interval $=1.36-3.33)$; the adjusted mean estimated costs of diabetes-related hospitalizations per patient were $\$ 2,792$ and $\$ 6,759$, respectively. ${ }^{14}$ In a systematic review of the literature (January 2000-November 2005) assessing the effect of antidiabetic medications and glycemic control on cost in patients with diabetes who were members of U.S. managed care organizations, investigators identified 8 studies showing that improved glycemic control reduces overall perpatient direct costs; of interest, the pharmacy component usually represented $20 \%$ to $30 \%$ of overall costs, and about 30\% of pharmacy charges were directly correlated with glycemic control. ${ }^{15}$

The current analysis was based on a hypothetical cohort of commercially insured and Medicare fee-for-service patients with type 2 diabetes who were identified from the NHANES database. Applying the United Kingdom Prospective Diabetes Study (UKPDS) complication risk model to the individual's risk characteristics, the analysis simulated diabetes complication rates under status quo risk factor profiles and complication reductions associated with improved management of Alc, BP, and lipids. Data extracted from large commercial and Medicare administrative databases were used to quantify the average incremental cost of 7 UKPDS diabetes complications for the year of the complication and the 2 years following a complication, with the cost impact presented in per-diabetes patient-per-month (PPPM) dollars. Using the claim costs associated with diabetes-related complications to model the costeffectiveness of improving diabetes care has been suggested by others. ${ }^{7}$ Previous cost studies examined subsets of managed care diabetes patients, analyzing both claims and clinical data. These studies compared costs among patients with varying levels of Alc and made adjustments to control for confounding variables. The potential selection biases of such approaches are well known, and results can reflect well-motivated patients or regression to the mean. Our approach of examining a 
hypothetical cohort of all diabetics sets boundaries for the maximum impact of better diabetes management on complications and cost and considers BP, lipid, and Alc control for a commercially insured population separate from the Medicare population.

\section{Methods}

\section{Data Sources}

Two NHANES series (2005-2006 and 2007-2008), with a total sample size of approximately 10,000 individuals, were analyzed to identify the prevalence of type 2 diabetes and distribution of risk characteristics in commercially insured and Medicare populations (see Appendix A for identification criteria [available in online article]). NHANES is produced by the National Center for Health Statistics, a department within the Centers for Disease Control and Prevention, and is based on a sample of the noninstitutionalized civilian population aged 12 years and older. The data items in NHANES include more than 1,000 items pertaining to an individual's clinical, demographic, and health status. Individuals were selected from NHANES using a stratified multistage sampling design. An insurance identifier provided for each individual in NHANES was used to select individuals whose primary payer was commercial insurance or Medicare.

The Thomson Reuters MarketScan Commercial Claims and Encounters Database (2006-2009) and Medicare 5\% sample data (2006-2009) were used to develop both the average annual costs and the PPPM and per-member-per-month (PMPM) costs in commercially insured and Medicare fee-for-service patients. PMPM costs were developed for the entire commercial and Medicare populations; PPPM costs were developed for patients with diabetes as were the per-patient cost of diabetes-related complications. The Thomson Reuters MarketScan database contains all paid claims generated by more than 20 million commercially insured lives annually. Member identification codes are consistent from year to year and allow for multiyear longitudinal studies. The database contains information about International Classification of Diseases, Ninth Revision, Clinical Modification (ICD-9-CM) diagnosis codes; procedure codes and diagnosis-related group (DRG) codes; national drug codes (NDCs); and site of service information and the amounts paid by commercial insurers. We identified costs as falling into the inpatient setting, outpatient setting, or prescription drugs based on assignments in MarketScan. The Medicare 5\% sample contains Medicare paid claims generated by a balanced sample of approximately 2.2 million beneficiaries. The sample contains information about ICD-9-CM diagnosis, procedure, and DRG codes, as well as site of service information, beneficiary age, eligibility status, and an indicator for HMO enrollment. We categorized costs into inpatient facility, outpatient facility, professional (inpatient or outpatient), skilled nursing facility, home health, and durable medical equipment (DME) or hos- pice, based on categories assigned in the Medicare 5\% sample Claims for prescription drug benefits, which are paid through Medicare Part D, are not included in the Medicare 5\% sample data and do not appear in our analysis. The 2 claims databases, the Medicare 5\% sample, and MarketScan were separately used as sources for Medicare and commercially insured lives, respectively, to generate estimated cost per diabetes complication in the year of the complication and in the 2 subsequent years.

The Milliman Health Cost Guidelines 2011 were used to adjust the NHANES population demographics to reflect typical age-sex distributions of Medicare 65+, non-Medicaid, and commercial beneficiaries. The guidelines provide a flexible (but consistent) basis for the determination of health claim costs and premium rates for a wide variety of health plans.

\section{Population Sample}

The NHANES database was used to identify patients with diabetes. Patients were considered to have diabetes if they answered "yes" to any of the following survey questions:

- Other than during pregnancy, has a doctor told you that you have diabetes? (NHANES field DIQ010)

- Are you now taking insulin? (NHANES field DIQ050)

- Do you take diabetes pills to lower blood sugar? (NHANES fields DIQ070, DID070)

NHANES does not specify whether a patient has type 1 or type 2 diabetes; therefore, we used previously published logic to exclude patients presumed to have type 1 diabetes. ${ }^{16}$ Patients answering "yes" to the first 2 questions and "no" to the third question below were excluded:

1 . Were you younger than the age of 31 years at the time of diabetes diagnosis? (DIQ040)

2. Are you now taking insulin? (DIQ050)

3. Do you take diabetes pills to lower blood sugar? (DIQ070/ DID070)

The diabetes sample included 466 commercially insured individuals aged 20-64 years (mean age, 53 years [SD, 9.2 years]; females, 53\%) and 392 Medicare beneficiaries aged 65 years and older (mean age, 73.5 years [SD, 5.5 years]; females, 46\%; Figure 1).

To establish baseline costs for diabetics and diabetes complications, 2006-2009 Thomson Reuters MarketScan and Medicare 5\% sample claims data were analyzed. For the baseline cost of diabetics, a patient was considered to have diabetes if he or she had 1 of the following: 1 inpatient claim, 1 emergency room (ER) claim, or 2 physician evaluation and management claims on separate days during January 2008 through December 2009 with ICD-9-CM 250.xx code as either the primary or secondary code. MarketScan includes pharmacy claims data, and for commercial members, we used the additional Healthcare Effectiveness Data and Information 


\section{FIGURE 1 Flowchart of NHANES Patient Selection}

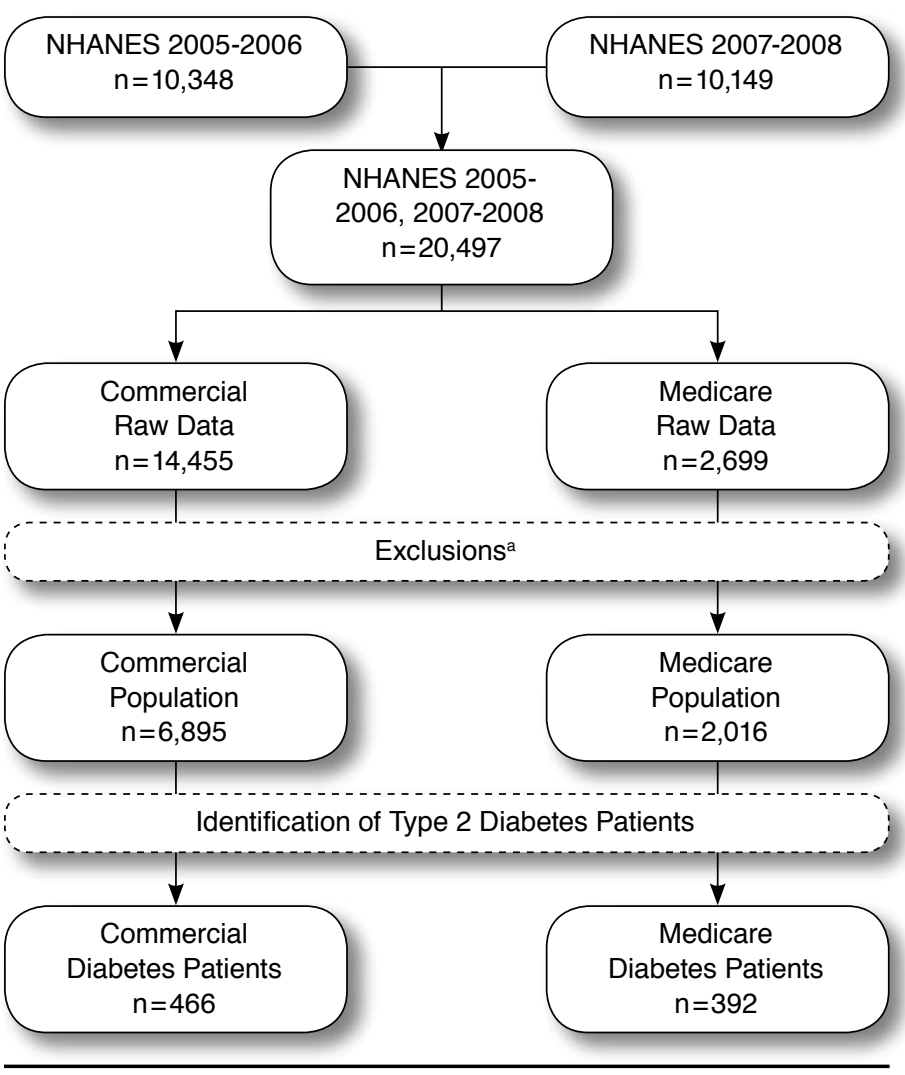

a Excluded age $<20$ or age $>64$ in commercial, age $<65$ in Medicare, or people not well populated in blood pressure/body mass index.

NHANES = National Health and Nutrition Examination Survey.

Set (HEDIS) diabetes identification criteria, 1 physician evaluation and management claim coded with ICD-9 250.xx as either the primary or a secondary code and 1 or more prescription claim(s) for a diabetes drug to determine if a patient had diabetes for this cohort. (NDC list available from HEDIS.) The Medicare data did not include prescription drug information, and we did not use this additional criteria for Medicare. Women having 1 or more claims coded with pregnancy-related diabetes (ICD-9-CM codes 630.xx-679.1 and 760.xx-779.9) were excluded from the diabetes cohort. The number of diabetics identified for the baseline costs from the commercial MarketScan analysis was 174,886 and for the Medicare 5\% analysis 260,682.

To calculate the cost of complications, 2006-2009 claims data were used to allow for calculation of the cost in the year prior to and the 2 years after the complication. The sample size of diabetics with each of the 7 complications is presented in Table 1.

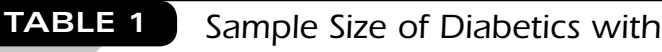
Complications

\begin{tabular}{l|c|c}
\hline Diabetes Complication & MarketScan & Medicare 5\% Sample \\
\hline Ischemic heart disease & 27,635 & 48,064 \\
\hline Myocardial infarction & 1,773 & 5,710 \\
\hline Congestive heart failure & 12,328 & 40,189 \\
\hline Stroke & 954 & 5,231 \\
\hline Amputation & 636 & 2,294 \\
\hline Blindness & 1,549 & 3,806 \\
\hline Renal failure & 7,590 & 13,041 \\
\hline
\end{tabular}

Source: Authors' analysis of MarketScan and Medicare 5\% sample 2006-2009.

\section{Study Measures}

The probability of developing a diabetes complication was calculated for each NHANES diabetes patient using the UKPDS risk model. The UKPDS risk model, a type 2 diabetes-specific risk calculator based on 53,000 patient-years of data from the UKPDS, ${ }^{17}$ determines the probability of developing each of 7 diabetes complications: ischemic heart disease, myocardial infarction, congestive heart failure (CHF), stroke, amputation, blindness, and renal impairment. The model includes formulae for calculating comorbidity incidence, estimates of probability for coronary heart disease (CHD) complications, and the relative risks correlated with potential risk factors, as well as equations for absolute risk that incorporate the effect of multiple risk factors to produce overall event rates. ${ }^{17}$ The UKPDS model includes the patient's Alc, systolic BP, and lipid levels as risk factors, in addition to age, sex, ethnicity, smoking status, and time since diabetes diagnosis. ${ }^{17}$ The NHANES risk factor fields used as inputs to UKPDS are presented in Appendix A (available in online article).

Costs of complications were developed by examining the actual claims costs of individuals having events. For each patient having an event, costs were tabulated in the year before the event, the year of the event, and 2 years after the event. Index year 2007 was used to identify the 7 diabetes complications (see Appendix B for coding logic used to identify complications [available in online article]). In order to represent the cost of each newly developed complication, 2006 was used to perform a 12-month look back from the index complication date to exclude patients from the cost calculation having claims coded with each of the 7 diabetes complications. The years 2008 and 2009 were used to follow the costs in the 2 years after the index complication.

We considered the complication costs that could be avoided to be the incremental cost of each complication-that is, the cost associated with the complication above the background cost of the diabetes patient. The incremental cost of each diabetes complication was the net of the costs in the year of the complication and the year prior to the complication and likewise for each of the 2 years after the complication, since 
TABLE 2 Clinical Targets and Improvement Scenarios

\begin{tabular}{|c|c|c|c|c|c|}
\hline & \multirow{2}{*}{\multicolumn{2}{|c|}{ ADA Clinical Targets }} & \multicolumn{3}{|c|}{ Improvement Amount } \\
\hline & & & Scenario 1 & Scenario 2 & Scenario 3 \\
\hline Alc (\%) & \multicolumn{2}{|c|}{$<7 \%$} & $\downarrow 1 \% \mathrm{Alc}$ & $\downarrow 1.25 \% \mathrm{Alc}$ & $\downarrow 1.5 \% \mathrm{Alc}$ \\
\hline Systolic BP/diastolic BP (mm Hg) & \multicolumn{2}{|c|}{$<130 / 80 \mathrm{~mm} \mathrm{Hg}$} & $\downarrow 10 \mathrm{~mm} \mathrm{Hg}$ & $\downarrow 20 \mathrm{~mm} \mathrm{Hg}$ & $\downarrow 30 \mathrm{~mm} \mathrm{Hg}$ \\
\hline High-density lipoprotein (mg/dL) & $>40 \mathrm{mg} / \mathrm{dL}(\mathrm{M})$ & $>50 \mathrm{mg} / \mathrm{dL}(\mathrm{F})$ & $\uparrow 20 \%$ & $\uparrow 35 \%$ & $\uparrow 50 \%$ \\
\hline Total cholesterol (mg/dL) & \multicolumn{2}{|c|}{$<200 \mathrm{mg} / \mathrm{dL}$} & $\downarrow 20 \%$ & $\downarrow 35 \%$ & $\downarrow 50 \%$ \\
\hline
\end{tabular}

patient costs rarely revert to precomplication costs. PPPM costs (i.e., the average monthly costs for the patient experiencing the event) were developed, and costs were trended from 20062009 to 2012 using a 5\% annual trend. The 5\% annual trend was chosen to approximate the combined effect of unit price and utilization trends across the commercial and Medicare populations during this period, although we note reports of higher and lower trends. ${ }^{18,19}$ Appendix C (available in online article) contains an algebraic presentation of the incremental cost calculation.

We did not include the additional costs of the pharmaceutical treatments or care management services that would be needed to achieve the improved outcomes we modeled. The availability of many generic drugs for glycemic, BP, and lipid control suggests relatively low additional costs are possible for the pharmaceutical treatments, at least for many patients. Care management programs come in many varieties and include electronic interfaces as well as more traditional telephonic outreach to patients by nurses. A full consideration of these costs is outside the scope of this analysis.

\section{Modeling Analysis}

Using the hypothetical cohort of commercially insured and Medicare fee-for-service patients with diabetes identified in the NHANES analysis as described earlier, the probability of diabetes-related complications for each patient was estimated using the UKPDS risk model. Using each patient's "status quo" (as appears in NHANES) risk factors, the probability of developing each complication was calculated, and that calculation was repeated for 3 improvement scenarios. The 3 improvement scenarios modified clinical metrics in patients with Alc, BP, total cholesterol, or high-density lipid protein cholesterol (HDL-C) not at recommended targets. The impact of reducing these metrics on status quo diabetes complication rates and the number of deaths associated with these complications was modeled in commercially insured and Medicare populations. The 3 improvement scenarios (Table 2) are based on American Diabetes Association (ADA) targets, and reductions in each of the 3 values are consistent with reductions generally achievable with initiation, titration, or add-on drug class therapy.

\section{Results}

The overall prevalence of type 2 diabetes in NHANES 20052008 is $6.1 \%$ in commercially insured adults aged 20 to 64 years and $19.4 \%$ in Medicare beneficiaries aged 65 years and older.

According to our analysis of NHANES data (2005-2008), the portion of individuals with type 2 diabetes attaining ADA recommended targets (Alc $<7 \%$; $\mathrm{BP}<130 / 80 \mathrm{~mm} \mathrm{Hg}$; LDL-C $<100 \mathrm{mg} / \mathrm{dL}$; total cholesterol <200 mg/dL; and HDL-C > 40 $\mathrm{mg} / \mathrm{dL}$ in men and $>50$ in women $)^{20}$ remains low. As shown in Figure 2, the Alc goal was attained by 53\% of commercially insured patients and 62\% of Medicare beneficiaries; total cholesterol, 61\% and 77\%, respectively; HDL-C, 53\% and 56\%, respectively; and BP, 49\% and 40\%, respectively. Only 9\% of commercially insured patients and $12 \%$ of Medicare beneficiaries had met all 3 target metrics.

\section{Diabetes Costs by Major Service Category by Payer}

The allowed PPPM cost in adult individuals with type 2 diabetes in the commercial population was found to be $\$ 1,090$, which compared with an average allowed PPPM cost of $\$ 448$ across the commercially insured adult population without diabetes and $\$ 489$ across the total adult population. The cost of the complications we analyzed (UKPDS complications) contributed $20 \%$ of the total spending in individuals with diabetes (Table 3).

Based on our analysis, the PPPM cost in the Medicare population claims analysis was found to be $\$ 1,565$, which compared with an average cost of $\$ 686$ for Medicare beneficiaries without diabetes and $\$ 858$ for the total Medicare population-each of these Medicare figures do not include spending on drugs. The cost of UKPDS complications contributed 21\% of the total spending for individuals with diabetes (Table 4).

\section{Probability of Diabetes Complications and the Impact of Better Diabetes Control on the Probability of Complications}

In the commercial population, improved management scenarios 1,2 , and 3 (see Table 2) produced reductions in the probability of diabetes-related complications of $43 \%, 55 \%$, and $67 \%$, respectively. In the Medicare population, the scenarios produced reductions in the probability of diabetes-related complications of $28 \%, 38 \%$, and $49 \%$. 


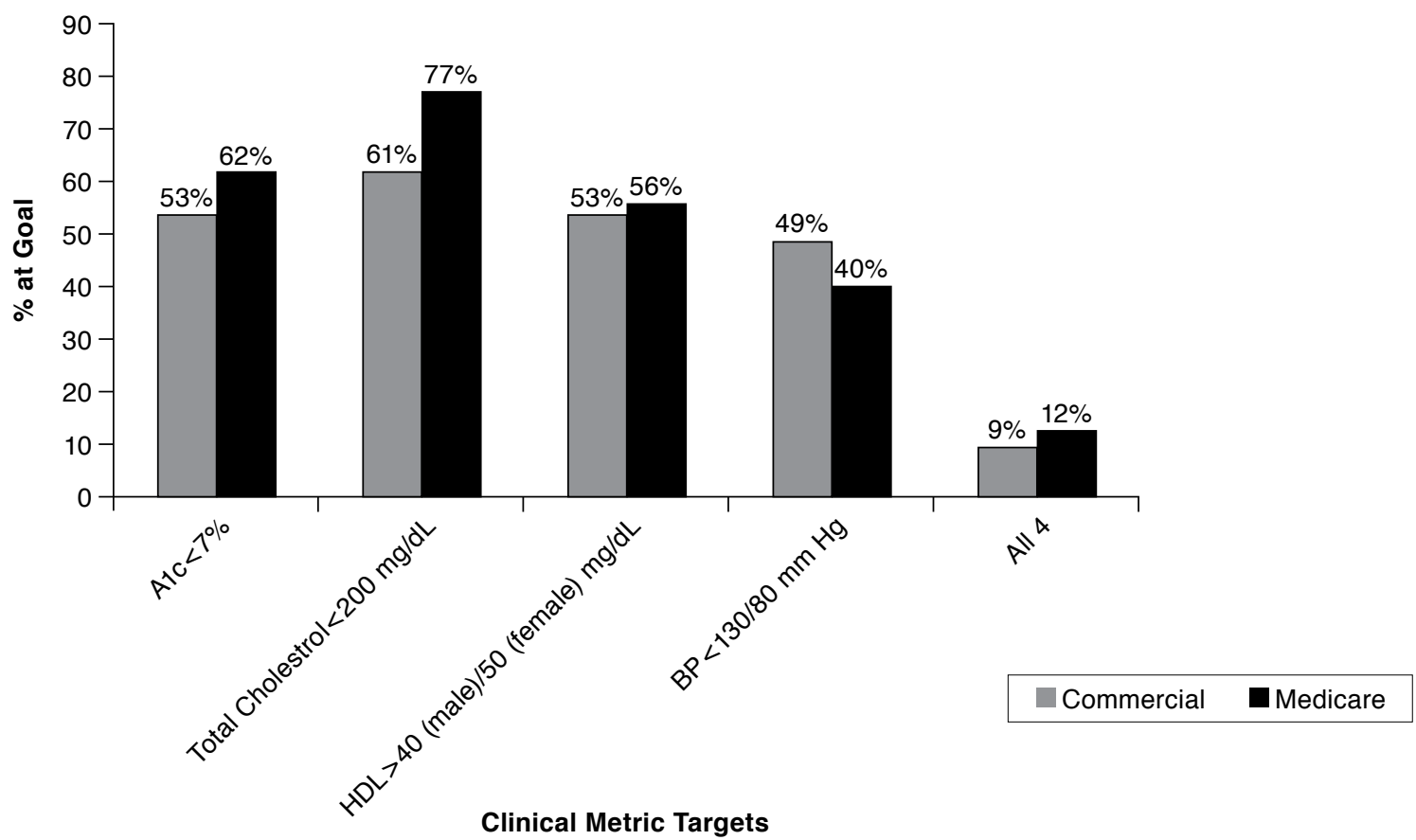

Source: Authors' analysis of NHANES 2005-2008 data.

Alc =hemoglobin $A 1 c ; B P=$ blood pressure; $H D L=$ high-density lipoprotein; $m g / d L=$ milligrams per deciliter; $m m \mathrm{Hg}=$ millimeter of mercury; NHANES=National Health and Nutrition Examination Survey.

\begin{tabular}{|c|c|c|c|}
\hline \multirow[t]{2}{*}{ T } & \multicolumn{3}{|c|}{$\begin{array}{l}\text { Allowed Cost PPPM by Major Service } \\
\text { Category in Commercial Population }\end{array}$} \\
\hline & & PPPM (\$) & $\begin{array}{c}\text { Total } \\
\text { Percentage }\end{array}$ \\
\hline \multirow[t]{7}{*}{ Total } & & 1,090 & 100 \\
\hline & UKPDS complications & 214 & 20 \\
\hline & Other than UKPDS complications & 876 & 80 \\
\hline & Diabetes prescription drugs & 86 & 8 \\
\hline & Other prescription drugs & 188 & 17 \\
\hline & $\begin{array}{l}\text { Inpatient, including } \\
\text { inpatient professional }\end{array}$ & 181 & 17 \\
\hline & $\begin{array}{l}\text { Outpatient, including } \\
\text { outpatient professional }\end{array}$ & 421 & 39 \\
\hline
\end{tabular}

Source: Authors' analysis of MarketScan 2006-2009, demographically adjusted to Milliman Health Cost Guidelines 2011.52 Costs trended to 2012.

PPPM = per patient per month; UKPDS = United Kingdom Prospective Diabetes Study.

Figures 3 and 4 provide the comparison of probability rates under the status quo and 3 management scenarios.

\section{Cost Impact of Better Diabetes Control}

The reduction in UKPDS complications was monetized under the 3 improvement scenarios. UKPDS complications were shown to account for approximately $20 \%$ of costs in individuals

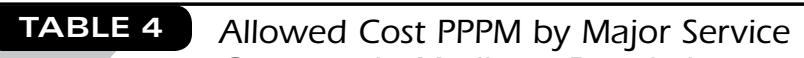
Category in Medicare Population

\begin{tabular}{|c|c|c|c|}
\hline & & PPPM (\$) & $\begin{array}{c}\text { Total } \\
\text { Percentage }\end{array}$ \\
\hline \multicolumn{2}{|l|}{ Total } & 1,565 & 100 \\
\hline & UKPDS complications & 331 & 21 \\
\hline & Other than UKPDS complications & 1,234 & 79 \\
\hline & Inpatient facility & 285 & 23 \\
\hline & Skilled nursing facility & 62 & 5 \\
\hline & Home health services & 57 & 5 \\
\hline & Outpatient facility & 152 & 12 \\
\hline & Physician professional & 336 & 27 \\
\hline & Durable medical equipment & 64 & 5 \\
\hline & Hospice & 18 & 1 \\
\hline
\end{tabular}

Source: Authors' analysis of Centers for Medicare and Medicaid Services' 5\% Medicare sample 2009, demographically adjusted to Milliman Medicare Health Cost Guidelines 2011. ${ }^{52}$ Costs trended to 2012.

PPPM = per patient per month; UKPDS = United Kingdom Prospective Diabetes Study.

with diabetes. The portion and type of complication avoided varied by the profile of each payer cohort and the reduction scenarios (Table 5). The cost savings impact from reduced complications across all diabetes patients on a PPPM basis ranged from $\$ 67$ to $\$ 105$ in the commercial population and $\$ 99$ to 


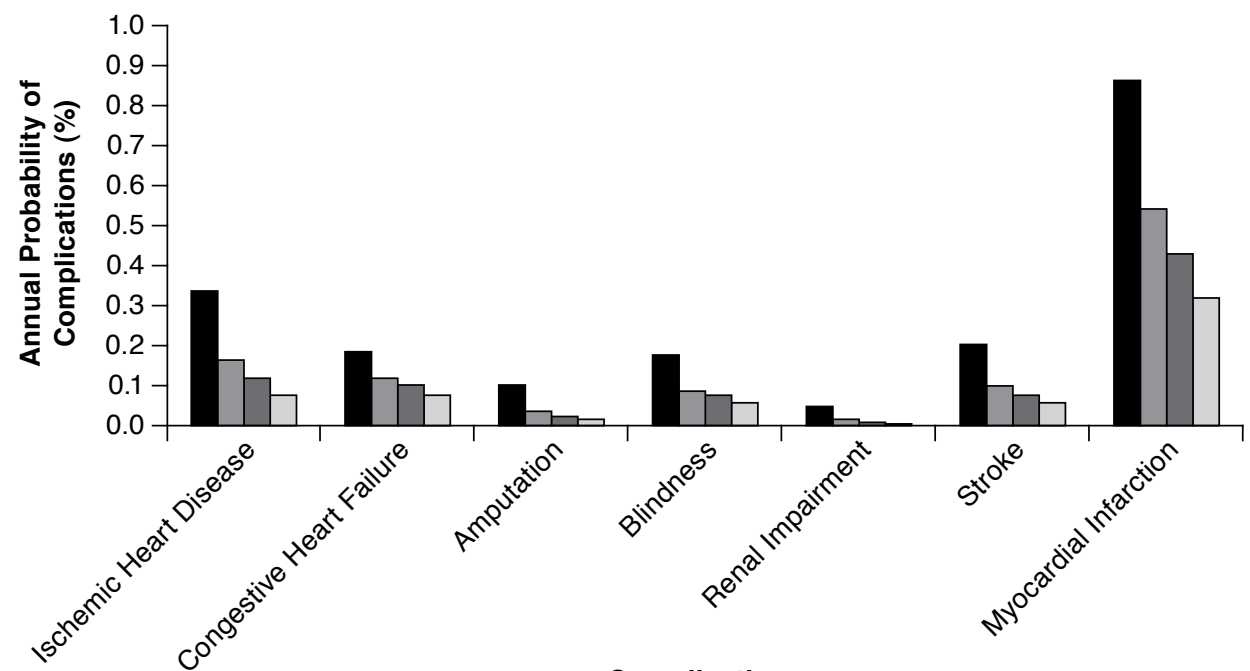

Status Quo

Senario 1

Senario 2

Senario 3

Source: Authors' analysis of NHANES 2005-2008 and UKPDS modeling.

NHANES = National Health and Nutrition Examination Survey; UKPDS= United Kingdom Prospective Diabetes Study.

\section{FIGURE 4 Impact of Better Control on Probability of Complications for Medicare Type 2 Diabetes}

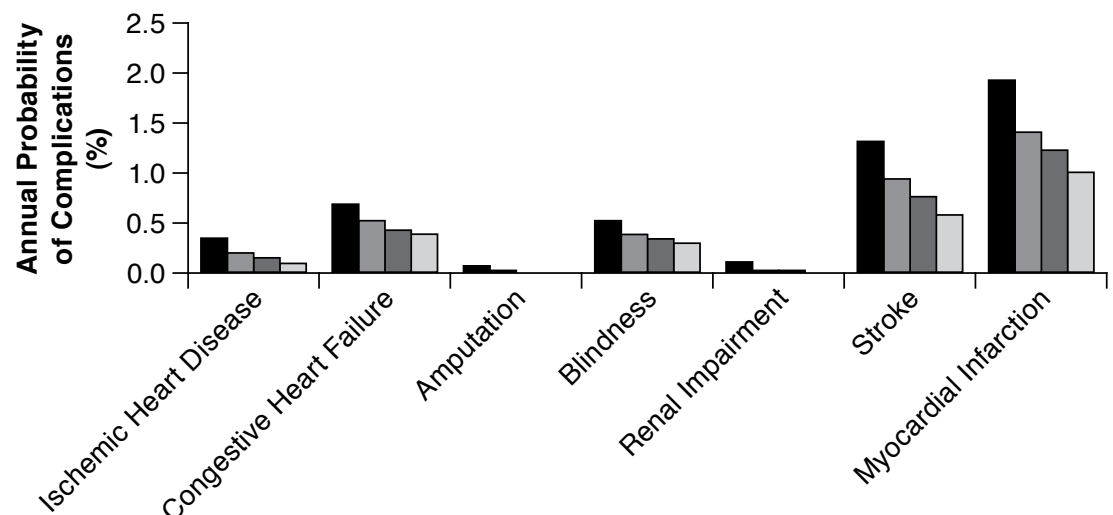

Status Quo

Senario 1

Senario 2

Senario 3
$\$ 158$ in the Medicare population. The high end of this savings range yielded a reduction of about $10 \%$ in total costs relative to an average of \$1,090 PPPM in commercially insured patients with diabetes and an average of \$1,565 PPPM in Medicare patients with diabetes.

In the commercial population, scenario 3 produced a $\$ 105.47$ PPPM reduction in costs (about $10 \%$ of the $\$ 1,090$ average monthly costs) in individuals with diabetes and a $\$ 4.70$ PMPM reduction in costs (about $1 \%$ of the $\$ 489$ aver- age monthly costs) across all insured members. As noted previously, the Medicare population with diabetes has higher complication risks but lower potential reduction in complications, compared with commercially insured populations. In the Medicare population with diabetes, scenario 3 produced a $\$ 106.04$ PPPM reduction in costs (about $7 \%$ of the $\$ 1,565$ average monthly costs) in individuals with diabetes and a $\$ 16.18$ reduction in PMPM costs (about 2\% of the $\$ 858$ average monthly costs) across all Medicare members. 
Medical Claim Cost Impact of Improved Diabetes Control for Medicare and Commercially Insured Patients with Type 2 Diabetes

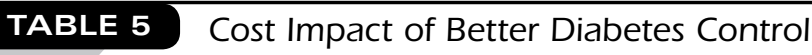

\begin{tabular}{|c|c|c|c|c|c|c|}
\hline \multirow[b]{2}{*}{ Commercial Population } & \multicolumn{3}{|c|}{ Target: All Diabetes Patients with Any Uncontrolled Metric ${ }^{a}$} & \multicolumn{3}{|c|}{ Target: Uncontrolled Alc Diabetes Patients } \\
\hline & Scenario 1 & Scenario 2 & Scenario 3 & Scenario 1 & Scenario 2 & Scenario 3 \\
\hline Reduction in complication rate & $43 \%$ & $55 \%$ & $67 \%$ & $43 \%$ & $55 \%$ & $68 \%$ \\
\hline Savings PPPM & $\$ 66.73$ & $\$ 86.06$ & $\$ 105.47$ & $\$ 99.44$ & $\$ 128.71$ & $\$ 158.17$ \\
\hline Savings PMPM & $\$ 2.97$ & $\$ 3.83$ & $\$ 4.70$ & $\$ 2.06$ & $\$ 2.67$ & $\$ 3.28$ \\
\hline \multirow[t]{3}{*}{ Savings per target patient over 3 years } & $\$ 2,400$ & $\$ 3,100$ & $\$ 3,800$ & $\$ 3,600$ & $\$ 4,600$ & $\$ 5,700$ \\
\hline & \multicolumn{3}{|c|}{ Target: All Diabetes Patients with Any Uncontrolled Metric ${ }^{a}$} & \multicolumn{3}{|c|}{ Target: Uncontrolled Alc Diabetes Patients } \\
\hline & Scenario 1 & Scenario 2 & Scenario 3 & Scenario 1 & Scenario 2 & Scenario 3 \\
\hline Reduction in complication rate & $28 \%$ & $38 \%$ & $49 \%$ & $32 \%$ & $43 \%$ & $54 \%$ \\
\hline Savings PPPM & $\$ 58.85$ & $\$ 82.33$ & $\$ 106.04$ & $\$ 74.55$ & $\$ 100.38$ & $\$ 126.49$ \\
\hline Savings PMPM & $\$ 8.98$ & $\$ 12.56$ & $\$ 16.18$ & $\$ 4.35$ & $\$ 5.86$ & $\$ 7.38$ \\
\hline Savings per target patient over 3 years & $\$ 2,100$ & $\$ 3,000$ & $\$ 3,800$ & $\$ 2,700$ & $\$ 3,600$ & $\$ 4,600$ \\
\hline
\end{tabular}

Table 6 shows the application of these scenarios to a commercial plan with 100,000 members and an estimated 4,454 patients with diabetes. The probabilities reflect the underlying fluctuation of outcomes relative to the status quo forecast.

\section{Discussion}

This study modeled the impact on diabetes of multiple points of control that are important for people with diabetes. Clinical practice guidelines for diabetes care specify target levels for $\mathrm{Alc}, \mathrm{BP}$, and lipids and protocols for lifestyle and drug therapy to achieve these targets, yet adherence to these recommendations is low.

Much of the research in diabetes control is funded by the pharmaceutical industry. Not surprisingly, much of the research focuses on the important metrics and outcomes associated with classes of drugs of interest to particular manufacturers, especially glycemic control. Indeed, patient adherence to diabetes drug therapy, lifestyle recommendations, and physician practice patterns are identified as contributors to the poor rate of glycemic control. Research to date has documented wide variance in patient adherence to glycemic control management, including the filling of prescriptions. ${ }^{21-25}$ Studies consistently report physician delays in intensifying drug therapy when Alc is above goal, with many patients experiencing levels $>8 \%$, resulting in years of glycemic burden. ${ }^{26-30}$ Furthermore, diabetes is a progressive disease, with studies reporting an annual $0.15 \%$ increase in patients' Alc, even with appropriate management. ${ }^{31}$ However, as we identify, focusing on diabetes patients with poor glycemic control ignores a large number of uncontrolled patients and misses large opportunities for improved outcomes. Because of these challenges, numerous innovative approaches to working with physicians and patients are underway.
To address the need for improvement in physician practice patterns in diabetes care, physician pay for performance (P4P) initiatives have been implemented by many health plans. Several studies have reported improved quality and clinical metrics in individuals with diabetes when cared for by physicians in a P4P arrangement, compared with those cared for by physicians without a P4P arrangement. ${ }^{32-34}$ Another initiative aimed at improving physician care coordination for individuals with diabetes and other chronically ill patients is the medical home movement, which often incorporates a P4P arrangement. Several patient-centered medical home demonstrations have reported improvements in quality and clinical outcomes in diabetes patients cared for under this model. ${ }^{35}$

Educational and behavioral change initiatives are commonly used to improve patient self-management and typically include disease management (DM) programs and diabetes self-management education (DSME) interventions. Varying levels of success have been reported with DM and DSME interventions. Diabetes DM programs are now a mainstay of commercial insurance programs and are provided by in-house programs or through contracts with DM vendors. The model for these programs is telephonic outreach, supplemented with diabetes educational mailings, to diabetes members who are identified through claims data or provider referral. Outreach is tailored to the severity level and knowledge base of each diabetes member. The impact of lowering Alc on medical costs is mixed..$^{36-41}$ The recently reported outcomes of the Medicare Health Support Disease Management Pilot Program, which enrolled more than 100,000 individuals with diabetes in the intervention and approximately 60,000 in the control group, showed no evident reduction in the utilization of acute care or the cost of care. ${ }^{42}$

DSME is typically performed by diabetes educators and is a covered benefit by Medicare and many commercial payers. The 
Medical Claim Cost Impact of Improved Diabetes Control for Medicare and Commercially Insured Patients with Type 2 Diabetes

TABLE 6 Cost Impact of Better Diabetes Control: Commercial Population with 100,000 Members

\begin{tabular}{|c|c|c|c|c|c|}
\hline & & \multicolumn{4}{|c|}{ Target: All Diabetes Patients } \\
\hline & & Status Quo & Scenario 1 & Scenario 2 & Scenario 3 \\
\hline Annual complication rate & & $1.9 \%$ & $1.1 \%$ & $0.9 \%$ & $0.6 \%$ \\
\hline \multicolumn{3}{|c|}{ Reduction in complication rate relative to status quo } & $43 \%$ & $55 \%$ & $67 \%$ \\
\hline & \multicolumn{2}{|l|}{ Probability ${ }^{\mathrm{a}}$ of scenario results $>$ status quo } & 0.0007 & $<0.0001$ & $<0.0001$ \\
\hline \multirow{2}{*}{\multicolumn{2}{|c|}{$\begin{array}{l}\text { PPPM } \\
\text { Savings PPPM }\end{array}$}} & $\$ 1,089.95$ & $\$ 1,023.22$ & $\$ 1,003.89$ & $\$ 984.47$ \\
\hline & & & $\$ 66.73$ & $\$ 86.06$ & $\$ 105.47$ \\
\hline & \multicolumn{2}{|l|}{ Probability ${ }^{\mathrm{a}}$ of scenario results $>$ status quo } & 0.0502 & 0.0154 & 0.0035 \\
\hline \multicolumn{6}{|c|}{$\begin{array}{l}\text { aProbabilities were calculated based on a commercial plan with: } \\
\text { Number of members }=100,000 \\
\text { Estimated number of diabetes patients }=4,454 \\
\text { Coefficient of Variation }(\mathrm{CV}) \text { of diabetes patients PPPM }=2.6 \\
\text { PPPM = per patient per month. }\end{array}$} \\
\hline
\end{tabular}

American Association of Diabetes Educators represents diabetes educator professionals and provides definitions, standards of care, and goals for diabetes educators. Diabetes educators are typically certified diabetes educators (CDE) or board certified in advanced diabetes management (BC-ADM) and most often have a background in nursing, dietetics, and pharmacy. Self-management education can take place in individual or group settings. A positive short-term impact on reducing Alc and costs has been reported, but the benefit has been shown to decline a few months after the intervention ceases. . $^{39,40,43-47}$

Value-based benefit designs (VBBD) for commercially insured populations, in which copayments for chronic diabetes drug therapies are reduced, have been associated with improved patient compliance with diabetes drug therapy. ${ }^{48}$ Elasticity between utilization of health care services and member copayment level is well established and is the foundation of VBBD initiatives for improving compliance with chronic disease drug treatment therapies. One VBBD study reported that a $36 \%$ reduction in copayments for diabetes medication was associated with a reduction in the number of nonadherent patients by $30 \%{ }^{48}$

A variety of web- and phone-based systems are available to help manage diabetes. A new class of systems was cleared by the U.S. Food and Drug Administration as a mobile health device for virtual patient coaching. A randomized controlled trial reported statistically significant Alc reductions in individuals with type 2 diabetes using the new patient coaching device compared with such individuals receiving usual care. ${ }^{49}$ The patient coaching system includes diabetes management software that allows patients to enter diabetes self-care data into their personal computers or mobile phones and receive automated real-time educational, behavioral, and motivational messaging specific to the entered data, along with a health care provider portal allowing physicians to access patient data. ${ }^{49}$ The increased adoption of electronic medical records and e-prescribing should complement and enhance patient-centric digital solutions.
Despite these management programs and the availability of a broad spectrum of pharmacologic products, diabetes control rates remain low. Yet, the correlation between lower Alc levels and lower diabetes-related complication rates has been well documented. ${ }^{4-6}$ Furthermore, medical costs have been shown to be reduced in individuals with diabetes who have improved glycemic control., ${ }^{9} 10$

The shortfall in diabetes control is not for a lack of treatment options. Most benefit plans cover a broad spectrum of options, including a variety of generic and brand prescription drugs classes, insulins, monitors, pumps, clinician patient education, and DM programs. Clearly, the collection of options, which vary widely in terms of costs and efficacy, is not sufficient to solve the diabetes problem.

The quantitative findings in the current study support the value of effective systems of care for individuals with diabetes. Both clinical recommendations and system change advocates recognize the importance of managing the whole patient. Indeed, the current models suggest that the health status improvement and cost reduction of this approach is greater than succeeding with any one particular metric or any one class of drug.

\section{Limitations}

The present study has several limitations. The diagnosis, procedure, or other codes in administrative data may be incorrect or incomplete, and various biases could affect the claims that are coded. For example, the claims of less severe patients and patients with fewer health system interactions may be less likely to be identified. The costs we present are national averages, but costs in particular systems and situations could be much higher or lower. NHANES is an examination survey, with weights provided for individual data points to allow the researcher to extrapolate results to the U.S. population. Some data points, such as insurance coverage, are based on responses to questions, which could introduce biases.

Modeling in the current study is limited to the impact of improved diabetes management on reducing UKPDS diabetes 
complications, which account for $20 \%$ of total diabetes medical costs. The analysis does not consider any potential reduction (or increase) in the $80 \%$ of medical costs in the target populations other than these complications. In addition, the study does not consider potential reduction (or increase) in indirect costs of diabetes, such as lost work time, productivity, and disability, which are reported to be $33 \%$ of the total U.S. estimated $\$ 174$ billion cost (in 2007 dollars) associated with diagnosed diabetes. ${ }^{50}$ Costs for the current level of drug treatments in the commercial analysis were included, but costs for improved diabetes therapy were not. Diabetes therapy includes diet and exercise, as well as pharmaceutical (generic and brand name) medications. The additional costs of medications should be considered in evaluating the projected cost savings.

\section{Conclusion}

Diabetes is a highly prevalent disease that is often associated with debilitating complications. Of particular concern is the suboptimal management of critical clinical metrics, including Alc, BP, and lipids. Individuals with diabetes have higher rates of microvascular and macrovascular disease and morbidity/ mortality than do individuals without diabetes. Studies show, however, that lower Alc levels are associated with lower diabetes-related complications and reduced medical costs, although the ACCORD trial ${ }^{7}$ identified higher mortality among patients with Alc $<6 \%$, compared with a control group with Alc of $7 \%-7.9 \%$, and the ADVANCE trial identified that the reduction in major microvascular and macrovascular events was largely driven by a reduction in nephropathy. ${ }^{51}$ Data from the current claims data analysis corroborate these findings, showing that better control of Alc, BP, and lipids is associated with complication rate reductions and savings opportunities in commercially insured and Medicare patients with type 2 diabetes.

\section{Authors}

KATHRYN FITCH, RN, MEd, is Principal and Healthcare Consultant; BRUCE S. PYENSON, FSA, MAAA, is Principal and Consulting Actuary; and KOSUKE IWASAKI, FIAJ, MAAA, is Consulting Actuary, Milliman, Inc., New York, New York.

AUTHOR CORRESPONDENCE: Kathryn Fitch, RN, MEd, Milliman, One Pennsylvania Plaza, 38th Fl., New York, NY 10119. Tel.: 646.473.3000; Fax: 646.473.3199; E-mail: kate.fitch@millman.com.

\section{DISCLOSURES}

This study and the preparation of this manuscript were funded by AT\&T Services, Inc. Relevant clients of the authors in the past 5 years have included sanofi-aventis, Boehringer-Ingelheim, Takeda, and Pfizer.

Study concept and design were contributed by Fitch and Iwasaki, with assistance from Pyenson. Iwasaki was responsible for data collection, with assistance from Fitch and Pyenson. Data interpretation and the writing and revision of the manuscript were performed by Fitch and Pyenson, with assistance from Iwasaki.

\section{REFERENCES}

1. Cheung BM, Ong KL, Cherny SS, Sham PC, Tso AW, Lam KS. Diabetes prevalence and therapeutic target achievement in the United States, 1999 to 2006. Am J Med. 2009;122(5):443-53.

2. Huang ES, Basu A, O'Grady M, Capretta JC. Projecting the future diabetes population size and related costs for the U.S. Diabetes Care. 2009;32(12):2225-29. Available at: http://care.diabetesjournals.org/content/32/12/2225.full.pdf+html. Accessed June 22, 2013.

3. Centers for Disease Control and Prevention. 2011 national diabetes fact sheet: national estimates and general information on diabetes and prediabetes in the United States. Atlanta, GA: U.S. Department of Health and Human Services; 2011. Available at: http://www.cdc.gov/diabetes/pubs/factsheetll. htm. Accessed July 9, 2013.

4. Stratton IM, Adler AI, Neil HA, et al. Association of glycaemia with macrovascular and microvascular complications of type 2 diabetes (UKPDS 35): prospective observational study. BMJ. 2000;321(7258):405-12. Available at: http://www.ncbi.nlm.nih.gov/pmc/articles/PMC27454/pdf/405.pdf. Accessed June 22, 2013

5. Anonymous. Intensive blood-glucose control with sulphonylureas or insulin compared with conventional treatment and risk of complications in patients with type 2 diabetes (UKPDS 33). UK Prospective Diabetes Study (UKPDS) Group. Lancet. 1998;352(9131):837-53.

6. Selvin E, Marinopoulos S, Berkenblit G, et al. Meta-analysis: glycosylated hemoglobin and cardiovascular disease in diabetes mellitus. Ann Intern Med. 2004;141(6):421-31

7. National Heart Lung and Blood Institute. Questions and answers: action to control cardiovascular risk in diabetes (ACCORD) study. March 15, 2010 Available at: http://www.nhlbi.nih.gov/health/prof/heart/other/accord/q_a. htm. Accessed June 22, 2013.

8. Fitch K, Iwasaki K, Pyenson B. Improved management can help reduce the economic burden of type 2 diabetes: a 20 -year actuarial projection. Milliman Client Report. April 28, 2010. Available at: http://publications.milliman.com/publications/health-published/pdfs/improved-management-canhelp.pdf. Accessed June 22, 2013.

9. Shetty S, Secnik K, Oglesby AK. Relationship of glycemic control to total diabetes-related costs for managed care health plan members with type 2 diabetes. J Manag Care Pharm. 2005;11(7):559-64. Available at: http://www. amcp.org/data/jmcp/Original\%20Research_559_564.pdf.

10. Gilmer TP, O'Connor PJ, Manning WG, Rush WA. The cost to health plans of poor glycemic control. Diabetes. 1997;20(12):1847-53.

11. Aagren M, Luo W. Association between glycemic control and shortterm healthcare costs among commercially insured diabetes patients in the United States. J Med Econ. 2011;14(1):108-14.

12. The CDC Diabetes Cost-Effectiveness Group. Cost-effectiveness of intensive glycemic control, intensified hypertension control, and serum cholesterol level reduction for type 2 diabetes. JAMA. 2002;287(19);2542-51. Available at: http://jama.ama-assn.org/content/287/19/2542.full.pdf+html. Accessed June 22, 2013.

13. Menzin J, Langley-Hawthorne C, Friedman M, Boulanger L, Cavanaugh R. Potential short-term economic benefits of improved glycemic control: a managed care perspective. Diabetes Care. 2001;24(1):51-55. Available at: http://care.diabetesjournals.org/content/24/1/51.full.pdf+html. Accessed June 22, 2013.

14. Menzin J, Korn JR, Cohen J, et al. Relationship between glycemic control and diabetes-related hospital costs in patients with type 1 or type 2 diabetes mellitus. J Manag Care Pharm. 2010;16(4):264-75. Available at: http://www. amcp.org/data/jmcp/264-275.pdf.

15. Stephens JM, Botteman MF, Hay JW. Economic impact of antidiabetic medications and glycemic control on managed care organizations: a review of the literature. J Manag Care Pharm. 2006;12(2):130-42. Available at: http:// amcp.org/data/jmcp/subj_review_130-142.pdf. 
16. Koopman RJ, Mainous AG 3rd, Diaz VA, Geesey ME. Changes in age at diagnosis of type 2 diabetes mellitus in the United States, 1988 to 2000. Ann Fam Med. 2005;3(1):60-63.

17. Stevens RJ, Kothari V, Adler AI, Stratton IM; United Kingdom Prospective Diabetes Study (UKPDS) Group. The UKPDS risk engine: a model for the risk of coronary heart disease in type II diabetes (UKPDS 56). Clin Sci (Lond). 2001;101(6):671-79. Available at: http://www.clinsci.org/ cs/101/0671/1010671.pdf. Accessed June 22, 2013

18. Mayne L, Girod C, Weltz S. 2012 Milliman Medical Index. Milliman, Inc. May 15, 2012. Available at: http://insight.milliman.com/article. php?cntid=8078\&utm_source=milliman\&utm_medium=web\&utm content=MMI-mktg\&utm_campaign=Healthcare\&utm_ terms=Milliman+Medical+Index. Accessed June 22, 2013.

19. Fitch K, Iwasaki K, Kalin D, Pyenson B. Cost trends for chroniccondition cohorts with Medicare benefits. Milliman, Inc. May 1, 2008. Available at: http://insight.milliman.com/article.php?cntid=7170\&utm_ source $=$ search $\& u t m \_$medium $=$web\&utm_content $=7170 \& u t m \_$ campaign=Search. Accessed June 22, 2013

20. American Diabetes Association. Standards of medical care in diabetes-2011. Diabetes Care. 2011;34(Suppl 1):S11-S61. Available at: http:// www.ncbi.nlm.nih.gov/pmc/articles/PMC3006050/pdf/zdcS11.pdf. Accessed June 22, 2013.

21. Fischer MA, Stedman MR, Lii J, et al. Primary medication nonadherence: analysis of 195,930 electronic prescriptions. J Gen Intern Med. 2010;25(4):284-90. Available at: http://www.ncbi.nlm.nih.gov/pmc/articles/ PMC2842539/pdf/11606_2010_Article_1253.pdf. Accessed June 22, 2012.

22. Heisler M, Choi H, Rosen AB, et al. Hospitalizations and deaths among adults with cardiovascular disease who underuse medications because of cost: a longitudinal analysis. Med Care. 2010;48(2):87-94. Available at: http:// www.ncbi.nlm.nih.gov/pmc/articles/PMC3034735/pdf/nihms262571.pdf. Accessed June 22, 2012.

23. Cramer JA. A systematic review of adherence with medications for diabetes. Diabetes Care. 2004;27(5):1218-24. Available at: http://care.diabetesjournals.org/content/27/5/1218.full.pdf+html. Accessed June 22, 2013.

24. Ho PM, Rumsfeld JS, Masoudi FA, et al. Effect of medication nonadherence on hospitalization and mortality among patients with diabetes mellitus. Arch Intern Med. 2006;166(17):1836-41.

25. Lau DT, Nau DP. Oral antihyperglycemic medication nonadherence and subsequent hospitalization among individuals with type 2 diabetes. Diabetes Care. 2004;27(9):2149-53. Available at: http://care.diabetesjournals.org/content/27/9/2149.full.pdf+html. Accessed June 22, 2013.

26. Nichols G, Koo Y, Shah S. Delay of insulin addition to oral combination therapy despite inadequate glycemic control. J Gen Intern Med. 2007;22(4):453-58. Available at: http://www.ncbi.nlm.nih.gov/pmc/articles/ PMC1829438/pdf/11606_2007_Article_139.pdf. Accessed June 22, 2013.

27. Grant RW, Cagliero E, Dubey AK, et al. Clinical inertia in the management of type 2 diabetes metabolic risk factors. Diabet Med. 2004;21(2):150-55.

28. Ulcickas MT, Lafata JE, Koro C. et al. Time to pharmacotherapy change in response to elevated HbAlc test results. Curr Med Res Opin. 2006;22:1567-74.

29. Shah BR, Hux JE, Laupacis A, Zinman B, van Walraven C. Clinical inertia in response to inadequate glycemic control: do specialists differ from primary care physicians? Diabetes Care. 2005;28(3):600-06. Available at: http://care.diabetesjournals.org/content/28/3/600.full.pdf+html. Accessed June 22, 2013.

30. Peyrot M, Rubin RR, Lauritzen T, et al. Resistance to insulin therapy among patients and providers: results of the cross-national Diabetes Attitudes, Wishes, and Needs (DAWN) study. Diabetes Care. 2005;28(11):2673-79. Available at: http://care.diabetesjournals.org/content/28/11/2673.full.pdf+html. Accessed June 22, 2013.
31. Turner RC, Cull CA, Frighi V, Holman RR. Glycemic control with diet, sulfonylurea, metformin, or insulin in patients with type 2 diabetes mellitus: progressive requirement for multiple therapies (UKPDS 49). UK Prospective Diabetes Study (UKPDS) Group. JAMA. 1999;281(21):2005-12. Available at: http://jama.ama-assn.org/content/281/21/2005.full.pdf+html. Accessed June 22, 2013.

32. Chen JY, Kang N, Juarez DT, Hodges KA, Chung RS, Legorreta AP. Impact of a pay-for-performance program on low performing physicians. J Healthc Qual. 2010;32(1):13-21.

33. Coleman K, Reiter KL, Fulwiler D. The impact of pay-for-performance on diabetes care in a large network of community health centers. J Health Care Poor Underserved. 2007;18(4):966-83.

34. Curtin K, Beckman H, Pankow G, Milillo Y, Green RA. Return on investment in pay for performance: a diabetes case study. J Healthc Manag. 2006;51(6):365-374.

35. Bojadzievski T, Gabbay RA. Patient-centered medical home and diabetes. Diabetes Care. 2011;34(4):1047-53. Available at: http://www.ncbi.nlm.nih. gov/pmc/articles/PMC3064021/pdf/1047.pdf. Accessed June 22, 2013.

36. Bott DM, Kapp MC, Johnson LB, Magno LM. Disease management for chronically ill beneficiaries in traditional Medicare. Health Aff (Millwood). 2009;28(1):86-98. Available at: http://content.healthaffairs.org/content/28/1/86.full.pdf+html. Accessed June 22, 2013.

37. Villagra VG, Ahmed T. Effectiveness of a disease management program for patients with diabetes. Health Aff (Millwood). 2004;23(4):255-66. Available at: http://content.healthaffairs.org/content/23/4/255.full.pdf+html. Accessed June 22, 2013.

38. Walker EA, Schmukler C, Ullman R, Blanco E, Scollan-Koliopoulus M, Cohen HW. Results of a successful telephonic intervention to improve diabetes control in urban adults: a randomized trial. Diabetes Care. 2011;34(1):2-7. Available at: http://care.diabetesjournals.org/content/34/1/2.full.pdf + html. Accessed June 22, 2013.

39. Norris SL, Nichols PJ, Caspersen CJ, et al. The effectiveness of disease and case management for people with diabetes. A systematic review. Am J Prev Med. 2002;22(4 Suppl):S15-S38.

40. Norris SL, Lau J, Smith SJ, Schmid CH, Engelgau MM. Self-management education for adults with type 2 diabetes: a meta-analysis of the effect on glycemic control. Diabetes Care. 2002;25(7):1159-71. Available at: http://care.diabetesjournals.org/content/25/7/1159.full.pdf+html. Accessed June 22, 2013.

41. Sidorov J, Shull R, Tomcavage J, Girolami S, Lawton N, Harris R. Does diabetes disease management save money and improve outcomes? A report of simultaneous short-term savings and quality improvement associated with a health maintenance organization-sponsored disease management program among patients fulfilling health employer data and information set criteria. Diabetes Care. 2002;25(4):684-89. Available at: http://care.diabetesjournals.org/content/25/4/684.full.pdf+html. Accessed June 22, 2013.

42. McCall N, Cromwell J. Results of the Medicare Health Support diseasemanagement pilot program. N Engl J Med. 2011;365(18):1704-12.

43. Duncan I, Birkmeyer C, Coughlin S, Li QE, Sherr D, Boren S. Assessing the value of diabetes education. Diabetes Educ. 2009;35(5):752-60.

44. Rickheim PL, Weaver TW, Flader JL, Kendall DM. Assessment of group versus individual diabetes education: a randomized study. Diabetes Care. 2002;25(2):269-74. Available at: http://care.diabetesjournals.org/content/25/2/269.full.pdf+html. Accessed June 22, 2013.

45. Rashed SM. Cost outcomes of diabetes education in a specialized community pharmacy. Am J Pharm Benefits. 2010;2(7):421-28.

46. Garrett DG, Bluml BM. Patient self-management program for diabetes: first-year clinical, humanistic, and economic outcomes. J Am Pharm Assoc (2003). 2005;45(2):130-37. 
47. Welch G, Zagarins SE, Feinberg RG, Garb JL. Motivational interviewing delivered by diabetes educators: does it improve blood glucose control among poorly controlled type 2 diabetes patients? Diabetes Res Clin Pract. 2011;91(1):54-60. Available at: http://www.ncbi.nlm.nih.gov/pmc/articles/ PMC3011053/pdf/nihms253171.pdf. Accessed June 22, 2013.

48. Zeng F, An JJ, Scully R, Barrington C, Patel BV, Nichol MB. The impact of value-based benefit design on adherence to diabetes medications: a propensity score-weighted difference in difference evaluation. Value Health. 2010;13(6):846-52.

49. Quinn CC, Shardell MD, Terrin ML, Barr EA, Ballew SH, Gruber-Baldini AL. Cluster-randomized trial of a mobile phone personalized behavioral intervention for blood glucose control. Diabetes Care. 2011;34(9):1934-42.
50. American Diabetes Association. Economic costs of diabetes in the U.S. in 2007. Diabetes Care. 2008;31(3):596-615. Available at: http://care.diabetesjournals.org/content/31/3/596.full.pdf+html. Accessed June 22, 2013.

51. ADVANCE Collaborative Group. Intensive blood glucose control and vascular outcomes in patients with type 2 diabetes. $N$ Engl J Med. 2008;358(24):2560-72.

52. Milliman 2011 health cost guidelines. Milliman, Inc. Available at: http:// www.milliman.com/expertise/healthcare/products-tools/health-cost-guidelines/. Accessed July 9, 2013 


\section{APPENDIX A UKPDS Model Inputs and NHANES Fields}

\begin{tabular}{|c|c|c|}
\hline Input to UKPDS Model & NHANES Field & NHANES Descriptor \\
\hline Ethnicity & RIDRETHI & Race/ethnicity \\
\hline Gender & RIAGENDR & Gender \\
\hline Age at (diabetes) diagnosis (y) & DID040 & Age when first told you had diabetes \\
\hline Duration of diabetes (y) & DIQ220 & When was your diabetes diagnosed \\
\hline Weight (kg) & BMXWT & Weight $(\mathrm{kg})$ \\
\hline Height $(\mathrm{m})$ & BMXHT & Standing height $(\mathrm{cm})$ \\
\hline \multirow[t]{2}{*}{ Atrial fibrillation } & BPXPULS: answer \#2 & Pulse irregular (yes) \\
\hline & $\mathrm{d} 00022$ & Warfarin (yes) \\
\hline PVD & & Not available in NHANES \\
\hline Smoking & SMQ040 & Do you now smoke cigarettes (yes) \\
\hline Cholesterol (mmol/L) & LBDTCSI & Total cholesterol $(\mathrm{mmol} / \mathrm{L})$ \\
\hline HDL (mmol/L) & LBDHDDSI & Direct HDL-cholesterol (mmol/L) \\
\hline Systolic BP(mm Hg) & BPXSBP & Systolic BP \\
\hline Diastolic BP (mm Hg) & BPXDBP & Diastolic BP \\
\hline HbAlc (\%) & LBXGH & Glycohemoglobin (\%) \\
\hline Ischemic heart disease & MCQ160D & Ever told you had angina/angina pectoris (yes) \\
\hline Congestive heart failure (CHF) & MCQ160B & Doctor told you had CHF (yes) \\
\hline Amputation & & Not available in NHANES \\
\hline Blind & VIQ017 & Blind in both eyes (yes) \\
\hline Renal & KIQ022 & Ever told you had weak/failing kidneys (yes) \\
\hline Stroke & MCQ160f & Stroke (yes) \\
\hline Myocardial infarction & MCQ160e & Heart attack (myocardial infarction) (yes) \\
\hline \multicolumn{3}{|c|}{ UKPDS Model Outputs Generated for This Report } \\
\hline UKPDS Model Output & Interpretation & \\
\hline \multicolumn{3}{|l|}{ Ischemic heart disease } \\
\hline Myocardial infarction & Coronary artery disease & \\
\hline \multicolumn{3}{|l|}{ Congestive heart failure (CHF) } \\
\hline Stroke & Ischemic or hemorrhagic stroke & \\
\hline \multicolumn{3}{|l|}{ Amputation } \\
\hline \multicolumn{3}{|l|}{ Blindness } \\
\hline Renal impairment & End-stage renal disease & \\
\hline
\end{tabular}




\section{APPENDIX B Claims Data Identification of Complications}

\begin{tabular}{l|l}
\hline Ischemic stroke: 1 ER or 1 inpatient claim with ICD-9-CM code in the primary position of the claim \\
\hline ICD-9-CM Codes & Description \\
\hline 433.01 & Occlusion and stenosis basilar artery with cerebral infarction \\
\hline 433.11 & Occlusion and stenosis carotid artery with cerebral infarction \\
\hline 433.21 & Occlusion and stenosis vertebral artery with cerebral infarction \\
\hline 433.31 & Multiple and bilateral with cerebral infarction \\
\hline 433.81 & Other specified pre-cerebral artery with cerebral infarction \\
\hline 433.91 & Unspecified pre-cerebral artery with cerebral infarction \\
\hline 434.01 & Cerebral thrombosis with cerebral infarction \\
\hline 434.11 & Cerebral embolism with cerebral Infarction \\
\hline 434.91 & Cerebral artery occlusion, unspecified, with cerebral infarction \\
\hline $436 . \mathrm{xx}$ & Ischemic stroke \\
\hline
\end{tabular}

Hemorrhagic stroke: 1 ER or 1 inpatient claim with ICD-9-CM in the primary position of the claim

\begin{tabular}{l|l}
\hline ICD-9-CM Codes & Description \\
\hline $430 . x x$ & Subarachnoid hemorrhage \\
\hline $431 . x x$ & Intracerebral hemorrhage \\
\hline $432.0-432.9$ & Other \& unspecified intracranial hemorrhage \\
\hline
\end{tabular}

Coronary artery disease event: Inpatient admission with ICD-9-CM code of 410.xx for myocardial infarction in any position of the claim OR any claim with CPT or ICD-9-CM procedure code for coronary revascularization

\begin{tabular}{l|l}
\hline CPT Codes & ICD-9-CM Procedure Codes \\
\hline 33140 & 00.66 \\
\hline $92980-92982$ & $36.0 \mathrm{x}$ \\
\hline 92984 & $36.1 \mathrm{x}$ \\
\hline 92985 & $36.2 \mathrm{x}$ \\
\hline 92986 & \\
\hline 92995 & \\
\hline 92996 & \\
\hline $33510-33523$ & \\
\hline $33533-33536$ & \\
\hline
\end{tabular}

Amputation: 1 inpatient claim with an ICD-9-CM procedure code in primary position or any individual with claim for amputation CPT code

\begin{tabular}{l|l}
\hline CPT Codes & ICD-9-CM Procedure Codes \\
\hline $27590-27598$ & 84.1 \\
\hline 27880 & $84.10-84.17$ \\
\hline 27881 & \\
\hline 27882 & \\
\hline 27884 & \\
\hline 27886 & \\
\hline 27888 & \\
\hline 28800 & \\
\hline 28805 & \\
\hline 28810 & \\
\hline 28825 & \\
\hline
\end{tabular}




\section{APPENDIX B Claims Data Identification of Complications (continued)}

\begin{tabular}{l|l}
\hline \multicolumn{2}{l}{ End-stage renal disease: Any claim coded with 1 or more of the following CPT codes } \\
\hline CPT Codes & \\
\hline $90918-90925$ & \\
\hline 90935 & \\
\hline 90937 & \\
\hline 90940 & \\
\hline $90951-90970$ & \\
\hline
\end{tabular}

Ischemic heart disease: Inpatient, 1 ER, or 2 physician E\&M claims with any of the following ICD-9-CM codes in any position of the claim

\begin{tabular}{l|l}
\hline ICD-9-CD Codes & Description \\
\hline $411.1 \mathrm{x}$ & Intermediate coronary syndrome \\
\hline $411.8 \mathrm{x}$ & Acute coronary occlusion without myocardial infarction \\
\hline $413 . \mathrm{xx}$ & Angina pectoris \\
\hline $414.0 \mathrm{x}$ & Coronary atherosclerosis \\
\hline
\end{tabular}

Congestive heart failure: 1 inpatient, 1 ER, or 1 physician E\&M claim with ICD-9-CM code 428.xx in the any position of the claim

Blindness: 1 inpatient, or 1 ER or 2 physician E\&M claims with ICD-9-CM code 369.xx in any position of the claim

$\mathrm{CPT}=$ Common Procedural Terminology; EE $\mathrm{M}=$ evaluation and management ER=emergency room;

ICD-9-CM = International Classification of Diseases, Ninth Revision, Clinical Modification. 


\section{APPENDIX C Incremental Cost Calculation}

Total incremental cost in calendar year (CY) for each of commercial, Medicare, or Medicaid was calculated using the formula below:

$$
\operatorname{Total}(C Y)=\sum_{y r} \sum_{\text {Event }} \operatorname{Incr}(y r, \text { Event }) \times Y(C Y, y r \text { Event })
$$

Here,

Incr(yr, Event $)=$ Incremental Cost in Index Year $(y r)$ and Event Type (Event $)$ Per Event

(2012 basis, annual)

$Y(C Y, y r$ Event $)=$ Number of Events in Index Year $(y r)$ and Event Type $($ Event $)$ in Calender Year $(C Y)$

$C Y=$ Calender Year $(2012,2013$, or 2014)

$y r=$ Index Year (0 [(Event Year),] 1, or 2)

Event $=$ Types of Event, which are:

IHD = ischemic heart disease

MI = myocardial infarction

$\mathrm{HF}=$ heart failure

Stroke

AMP = amputation

$\mathrm{RF}=$ renal failure

Blindness

Incremental Cost in Index Year (Incr[yr, Event]), which is per event, was calculated using the formula below:

Incr(yr, Event)

$$
\begin{aligned}
& =\operatorname{Cost}(y r, \text { Event ECY }) \times(1+t)^{2012-E C Y-y r}-\operatorname{Cos} t(-1, \text { Event, ECY }) \\
& \times(1+t)^{2012-E C Y+1}
\end{aligned}
$$

Here,

$E C Y=$ Calendar Year of Event in the database

Cost $(y r$ Event, ECY $)=$ Average Annual Cost of Event Calendar Year $(E C Y)$, Index Year $(y r)$, and Event Type $($ Event $)$ per Event

$t=$ Annual Cost Trend (5\%)

In the case of blindness, we assumed

Cost $(y r$ Blindness, $E C Y)=\operatorname{Cost}(0$, Blindness, $E C Y)$ if $\mathrm{yr}=1$ or 2 . 